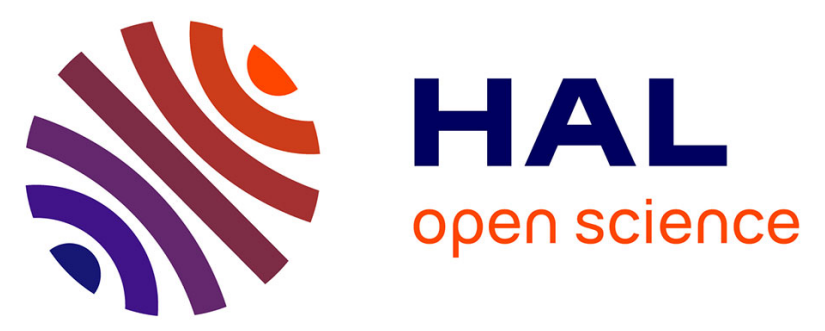

\title{
Biogeography of soil microbial communities: a review and a description of the ongoing french national initiative
}

Lionel Ranjard, Samuel S. Dequiedt, Claudy C. Jolivet, Nicolas P.A. Saby, Jean Thioulouse, Jérome Harmand, Patrice Loisel, Alain Rapaport, Saliou Fall, Pascal Simonet, et al.

\section{To cite this version:}

Lionel Ranjard, Samuel S. Dequiedt, Claudy C. Jolivet, Nicolas P.A. Saby, Jean Thioulouse, et al.. Biogeography of soil microbial communities: a review and a description of the ongoing french national initiative. Agronomy for Sustainable Development, 2010, 30 (2), pp.359-365. 10.1051/agro/2009033 . hal-00886549

\section{HAL Id: hal-00886549 \\ https://hal.science/hal-00886549}

Submitted on 1 Jan 2010

HAL is a multi-disciplinary open access archive for the deposit and dissemination of scientific research documents, whether they are published or not. The documents may come from teaching and research institutions in France or abroad, or from public or private research centers.
L'archive ouverte pluridisciplinaire HAL, est destinée au dépôt et à la diffusion de documents scientifiques de niveau recherche, publiés ou non, émanant des établissements d'enseignement et de recherche français ou étrangers, des laboratoires publics ou privés. 


\title{
Review article
}

\section{Biogeography of soil microbial communities: a review and a description of the ongoing french national initiative}

\author{
Lionel RANJARD $^{1,2 *}$, Samuel DEQUIEDT ${ }^{1,2}$, Claudy JOLIVET $^{3}$, Nicolas P.A. SABY $^{3}$,

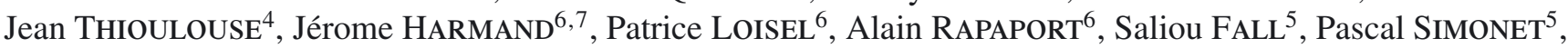 \\ Richard JofFrE $^{8}$, Nicolas CHEMIdLIN-PrÉvost Bouré ${ }^{1,2}$, Pierre-Alain MARON ${ }^{1,2}$, Christophe MougEL ${ }^{1,2}$, \\ Manuel P. MARTIN ${ }^{3}$, Benoît ToutAIN ${ }^{3}$, Dominique ArRouAYs ${ }^{3}$, Philippe LeMANCEAU ${ }^{1,2}$ \\ ${ }^{1}$ INRA-Université de Bourgogne, UMR Microbiologie du Sol et de l'Environnement, CMSE, 17 rue Sully, B.V. 86510, 21065 Dijon Cedex, France \\ ${ }^{2}$ Platform GenoSol, INRA-Université de Bourgogne, CMSE, 17 rue Sully, B.V. 86510, 21065 Dijon Cedex, France \\ ${ }^{3}$ INRA Orléans - US 1106, Unité INFOSOL, avenue de la Pomme de Pin, BP 20619, Ardon, 45166 Olivet Cedex, France \\ ${ }^{4}$ Université de Lyon, 69000 Lyon, France; Université Lyon 1, CNRS, UMR 5558, Laboratoire de Biométrie et Biologie Évolutive, 69622 Villeurbanne, France \\ ${ }^{5}$ Équipe "Génomique Microbienne Environnementale" (Environmental Microbial Genomics Group), UMR CNRS 5005, Laboratoire Ampère, \\ École Centrale de Lyon, 36 avenue Guy de Collongue, 69134 Ecully Cedex, France \\ ${ }^{6}$ INRA-INRIA MERE research project, UMR ASB, place Pierre Viala, 34060 Montpellier Cedex, France \\ ${ }^{7}$ LBE-INRA, UR050, avenue des étangs, 11100 Narbonne, France \\ ${ }^{8}$ UMR 5175 CNRS, Équipe DREAM - Centre d'Écologie Fonctionnelle et Évolutive, 1919 route de Mende, 34293 Montpellier Cedex 5, France
}

(Accepted 19 August 2009)

\begin{abstract}
Microbial biogeography is the study of the distribution of microbial diversity on large scales of space and time. This science aims at understanding biodiversity regulation and its link with ecosystem biological functioning, goods and services such as maintenance of productivity, of soil and atmospheric quality, and of soil health. Although the initial concept dates from the early 20th century (Beijerinck (1913) De infusies en de ontdekking der backterien, in: Jaarboek van de Knoniklijke Akademie van Wetenschappen, Muller, Amsterdam), only recently have an increasing number of studies have investigated the biogeographical patterns of soil microbial diversity. A such delay is due to the constraints of the microbial models, the need to develop relevant molecular and bioinformatic tools to assess microbial diversity, and the non-availability of an adequate sampling strategy. Consequently, the conclusions from microbial ecology studies have rarely been generally applicable and even the fundamental power-laws differ because the taxa-area relationship and the influence of global and distal parameters on the spatial distribution of microbial communities have not been examined. In this article we define and discuss the scientific, technical and operational limits and outcomes resulting from soil microbial biogeography together with the technical and logistical feasibility. The main results are that microbial communities are not stochastically distributed on a wide scale and that biogeographical patterns are more influenced by local parameters such as soil type and land use than by distal ones, e.g. climate and geomorphology, contrary to plants and animals. We then present the European soil biological survey network, focusing on the French national initiative and the "ECOMIC-RMQS" project. The objective of the ECOMIC-RMQS project is to characterise the density and diversity of bacterial communities in all soils in the RMQS library in order to assess, for the first time, not only microbial biogeography across the whole of France but also the impact of land use on soil biodiversity (Réseau de Mesures de la Qualité des Sols = French Soil Quality Monitoring Network, 2200 soils covering all the French territory with a systematic grid of sampling). The scientific, technical and logistical outputs are examined with a view to the future prospects needed to develop this scientific domain and its applications in sustainable land use.
\end{abstract}

soil biogeography / microbial communities / soil survey / microbial ecology / diversity

\section{INTRODUCTION}

Although microorganisms are the most diverse and abundant type of organism on earth (Gans et al., 2005; Curtis

* Corresponding author: ranjard@ dijon.inra.fr and Sloan, 2005), the determinism of microbial diversification and the distribution of microbial diversity from small to large scales has been poorly documented and is little understood. Most studies of prokaryote diversification have focused on variations due to mutations and/or lateral gene transfers and subsequent selection resulting from environmental 
stresses and competition for resources. Few have considered more neutral mechanisms, such as genetic drift due to physical isolation, thus revealing the crucial lack of integration of the spatial scale into microbial community assembly (Ranjard and Richaume, 2001; Papke and Ward, 2004).

Ecologists have long recognised that beta-diversity (how community composition changes across a landscape) is pivotal to understanding how environmental factors affect the magnitude and variability of biodiversity. This conceptual vision is also relevant to microorganisms since beta-diversity patterns offer valuable insights into the relative influence of dispersal limitations, environmental heterogeneity, and environmental and evolutionary changes in shaping the structure of ecological communities (Green et al., 2004). Although the spatial patterning of microbial diversity is known to have important consequences on plant community structure and ecosystem functioning, microbial beta-diversity patterns have been poorly investigated and remain largely unknown. The empirical relationship between the number of species and the area sampled (taxa-area relationship) has not been empirically examined in microorganisms, as it has in plants and animals (Horner-Devine et al., 2004; Green and Bohannan, 2006). This may partly be explained by the characteristics of microorganisms, namely (i) their small size, which makes access within environmental matrices difficult, (ii) their high density (e.g. more than one billion per gram of soil) and (iii) their huge diversity (from 1000 to 1000000 species per gram of soil, Torsvik and Øvreås, 2002), not to mention the complexity of precisely defining their species. Progress is also hampered by difficulties in designing an adequate sampling strategy. Such a strategy needs to integrate a large scale of sampling (region, territory, etc.), with precise squaring that is representative of any landscape modifications, which therefore implies a very large number (several thousands) of samples.

Our aim in this paper is to present the results of the first analytical studies of the biogeography of soil microbial communities, the concept applied and the technical feasibility of this novel scientific domain in environmental microbiology. We shall then describe the European strategy and the French national soil survey in which different research teams with scientific expertise in soil science, statistics, microbial ecology and geochemistry are, for the first time, working to assess the inventory and mapping of soil microbial diversity on a national territorial scale.

\section{SCIENTIFIC OUTCOMES OF MICROBIAL BIOGEOGRAPHY}

Biogeography is the study of the distribution of biodiversity over space and time (Martiny et al., 2006). In other words, the aim in biogeography is to reveal where organisms live and their abundance, and to determine those environmental factors that select or maintain the presence of these organisms. This scientific approach was first applied during the eighteenth century in studies of the geographic distribution of plant and animal diversity. These investigations provided insights into the mechanisms that generate and maintain diversity in macroor- ganisms e.g., speciation, extinction, dispersal and species interactions (Brown and Lomolino, 1998).

Despite the key role of microorganisms in a wide range of biogeochemical cycles, few studies (in comparison with macroorganisms) have examined the distribution of microbial diversity on a broader scale than field plots. The first study describing and investigating microbial biogeography was conducted by Beijerinck (1913), who stated that "everything is everywhere, but, the environment selects" (see Sect. 3). Since then, few authors have examined the full extent of microbial diversity or described the biogeographical patterns in an attempt to assess this statement and specify which environmental factors exert the strongest influence on indigenous microbial communities. Even though recent advances in molecular biology have led to the development of tools to assess bacterial diversity in environmental samples without culturing, most studies have focused on cataloguing the bacterial diversity in particular sites or describing how bacterial communities have been affected by environmental perturbations (for review see Ranjard et al., 2000). Thus, the conclusions of such microbial ecology investigations cannot be generally applied as the data from different studies are difficult to compare and the trends deduced are often inconsistent.

\subsection{Phylogeography of particular populations}

To date, most studies dealing with microbial biogeography have been limited to the phylo-geography of particular populations, particularly of pathogenic or symbiotic organisms. One of the main results is that many host-associated microorganisms exhibit genetic and functional patterns that are related to the distribution of their hosts (for review see Martiny et al., 2006). As regards the free-living microorganisms, most recent investigations have been focused on individual soil bacterial strains (Cho and Tiedje, 2000). These studies have tended to demonstrate that the genetic distance between microorganisms is related to geographic distance, and have highlighted correlations between assembly composition and environmental or geographic characteristics (for review see Martiny et al., 2006). Few publications have considered the soil microbial community as a whole and how it is structured on a large spatial scale.

\subsection{Biogeography of microbial communities}

In one of the rare studies available, Green et al. (2004) genotyped fungal community structure in numerous Australian soils (about 1500) and were able to demonstrate that despite the high local diversity of microorganisms, the regional diversity was only moderate. Fierer and Jackson (2006) produced a continent-scale description of soil bacterial diversity by considering about 100 different soils sampled from the north to south of America. By applying a DNA fingerprinting method, they demonstrated that bacterial diversity was unrelated to site temperature, latitude and other variables that, in contrast, strongly influence plant and animal diversity, and 
that community composition was largely independent of geographic distance. The environmental factor most influencing bacterial diversity was soil $\mathrm{pH}$, with the highest diversity occurring in neutral soils and the lowest in acidic soils. These studies also demonstrated that taxa-area relationships in soil microorganisms were weak, thus indicating that microbial biogeography differs fundamentally from that of "macroorganisms". By applying a pyrosequencing technique to ribosomal sequences in the same set of soil samples, Jones et al. (2009) defined the ecological attributes of particular populations such as Acidobacteria and confirmed the importance of soil $\mathrm{pH}$ in their dissemination.

In contrast, Johnson et al. (2003) demonstrated that variations in the genetic structure of bacterial communities from numerous agricultural soils were not correlated with $\mathrm{pH}$ but with soil texture and electrical conductivity. The overall inconsistency of these reports may possibly be ascribed to the inadequate sampling strategy in terms of number and representativeness of the soils sampled. However, it underlines the fact that the number of studies dealing with microbial-biogeography needs to be increased to understand the determinism of microbial diversity better, especially as this latter directly affects a wide range of ecosystem processes and therefore the quality of our environment.

\subsection{The first concept of microbial biogeography: "Beijerinck, 1913"}

Microbial ecologists describing biodiversity on a large spatial scale, i.e. microbial biogeography, generally invoke one of the oldest fundamental paradigms in microbial ecology, "everything is everywhere, but, the environment selects", proposed by Beijerinck (1913). This tenet was used as the starting point for studies of prokaryotic biodiversity and their biogeographical patterns but was frequently misinterpreted. Baas Becking (1934), and more recently de Witt and Bouvier (2006), rehabilitated the original meaning of this statement, which reflects an apparent contradiction between empirical observations that specific microorganisms are observed in their characteristic environments and the idea that all microorganisms are cosmopolitan. Despite the technical difficulty of verifying the first statement, due to the detection limits of the approaches used to characterise microbial diversity, this premise implies that the genetic cohesiveness of prokaryotic populations can never be broken by physical isolation but solely by adaptation. These basic concepts were only implicit in the publication of Beijerinck (1913) but were tacitly accepted (Baas Becking, 1934).

The concept "everything is everywhere" is supported by several particularities of the microbial model: microorganisms (i) are small and easily transported, (ii) are able to form a resistant physiological stage that allows them to survive in hostile environments, and (iii) have extremely large population sizes with a high probability of dispersal and a low probability of local extinction (Fenchel, 2003). The fact that more than $10^{18}$ $10^{20}$ microorganisms are estimated to be transported annually through the atmosphere between continents supports the hy- pothesis of a wide dispersion of microbes (Gans et al., 2005). Further evidence is that bacteria can be isolated from places where "they should not be", e.g. thermophilic bacteria from cold sea water (Isaksen et al., 1994).

In contrast, "the environment selects" might seem to challenge the concept that "everything is everywhere", and suggests that geographic isolation of populations coupled with limited dispersal leads to allopatric speciation. An increasing number of studies have demonstrated that the physical isolation of free-living microorganisms may be more widespread than previously thought (for review see Papke and Ward, 2004). However, most recent studies have been limited to characterisation of the culturable populations which are known to represent only a very small fraction of the whole community (Amann et al., 1995). To date, few studies have focused on microbial communities, possibly because of the technical limitations associated with identifying the huge microbial diversity in natural ecosystems and the difficulties in detecting minor populations. These technological limitations have now been partly resolved thanks to the recent development of molecular tools that circumvent the isolation and culture of organisms, and allow microbial community structure and diversity to be characterised without a priori knowledge (for review see Ranjard et al., 2000; Christen, 2008). Furthermore, these tools are now generally automated and allow the moderate throughput essential to studies involving the characterisation of numerous environmental samples.

\section{SOIL BIODIVERSITY MONITORING IN EUROPE}

\subsection{International context}

Although soil inventory programmes exist in all European countries, there are not many fully operational soil monitoring systems in Europe (Morvan, 2008). Few include more than one sampling point in time so that most are mere inventories. The only EU-wide soil monitoring network is the ICP forest level 1 grid, which was partly re-sampled in 2006-2007 within the Forest Focus BioSoil project (Lacarce et al., 2009). The data requirements for this re-sampling did not include microbial diversity. Progress in recent years has been hampered by a lack of perception of the importance of soil, data ownership issues and data incompatibility resulting from the multiplicity of different sampling and analytical procedures. The ENVASSO project addressed the need to characterise soils by setting up a series of interlinked objectives to harmonise the soil data sets that currently exist in EU Member States (Kibblewhite et al., 2008). Eight threats to soil (erosion, declining organic matter, contamination, compaction, salinisation, loss of biodiversity, soil sealing, landslides and flooding) have been identified in the European Commission's official Soil Communication part of the Thematic Strategy for Soil Protection in Europe. The aim of the ENVASSO project was to develop a system to harmonise existing, mostly national, data sets and provide a central reference point to assess current soil status and ensure sustainable management in the future. This project identified the 
physical and chemical parameters to monitor, most of which were already being monitored by the national soil surveys conducted in different European countries.

\subsection{The French soil survey: RMQS}

It was apparent from the initial data collected during the ENVASSO project that biodiversity was not fully included in any national soil monitoring network except in the Netherlands. In 2001, a new structure was created in France to reorganise soil mapping and soil monitoring programmes and to provide relevant insights into the spatial distribution of soils and the evolution of their properties. This structure, called the Scientific Group on Soils (GIS Sol) includes the Ministries of Agriculture and Environment, the Environment and Energy Management Agency (ADEME), the Research Institute for Development (IRD), the National Forest Inventory (IFN) and the National Institute of Agronomic Research (INRA). The main soil monitoring programme is the French Soil Quality Network ("Réseau de Mesures de la Qualité des Sols", RMQS), that is based on a $16 \mathrm{~km}$ by $16 \mathrm{~km}$ grid, with 2200 sites representative of the main soil systems and land uses in France. This configuration has the advantage of being fully compatible with the sites of the ICP forest level 1 network (now called BioSoil) which monitors forested soils across Europe. The RMQS is a complete and balanced network of 2200 sites which will be sampled every 10 years to monitor soil quality. The primary objectives of the network are to characterise and quantify diffuse contamination in trace elements (Saby et al., 2006) and to evaluate and monitor organic carbon stocks. For this purpose, a set of analyses (particlesize distribution, bulk density, $\mathrm{C}, \mathrm{N}, \mathrm{pH}$, trace elements, etc.) and a complete description of the soil profile at each site are obtained together with information about past activities, the environment, etc. Apart from these objectives, the network is responsible for many other soil quality evaluations and monitoring, e.g. persistent organic pollutants (pesticides, dioxins, organochlorides, $\mathrm{PAH}$, etc.).

\subsection{An Ongoing project: The ECOMIC-RMQS project}

Based on this soil survey, the scientific project "ECOMICRMQS" was set up in 2006, offering the first opportunity to implement biological diversity in a soil monitoring network. This project is coordinated by the Microbiology of the Soil and Environment Centre ("Centre de Microbiologie du Sol et de l'Environnement" i.e. CMSE, INRA Dijon, Burgundy, France) and is one of the first steps to demonstrate the technical feasibility and scientific relevance of federating European initiatives to monitor soil biodiversity monitoring.

The objective of the ECOMIC-RMQS project is to characterise the density, genetic structure and diversity of bacterial communities in all soils in the RMQS library (2200 soils sampled up to 2009) in order to assess, for the first time, not only microbial biogeography across the whole of France but also the impact of land use on soil biodiversity. The strategy for characterising the density and diversity of the bacterial communities relies on molecular tools such as quantitative PCR, DNA micro-array and DNA fingerprinting on soil DNA extracts (Fig. 1).

This integrated project will provide cognitive insights into the ecological theory on the community assembly by:

- elucidating the relative contribution of geographic isolation versus wide dispersal in limiting bacterial diversification,

- allowing better examination of the taxa-area relationship for bacteria,

- deciphering the hierarchy of the environmental parameters (plant cover, physico-chemical characteristics, climate factors, etc.) that most contribute to bacterial community diversity and composition.

This project should also have more applied outcomes as a result of:

- determining the state of bacterial diversity in French soils,

- better estimation of the impact of land use and human activities on microbial diversity and distribution,

- identifying bacterial bio-indicators specific to land management and human activities.

The ECOMIC-RMQS project provides an appropriate means of (i) assessing the microbial-biogeography by use of the RMQS and (ii) elucidating the determinisms of bacterial community diversification in soils better. This project should provide answers to some of the questions originating from mechanistic hypotheses:

- Are microbial communities a "black box" with no spatial structure or, like macroorganisms, do they exhibit a particular distribution with predictable, aggregated patterns from local to regional scales? In other words, does a taxaarea relationship exist in microbial-biogeography? (Green et al., 2004; Horner Devine et al., 2004).

- Are spatial variations due to contemporary environmental factors or to historical land use and contingencies?

- Which environmental factors (edaphic, climatic, land use, anthropogenic) most contribute to the structure and diversity of bacterial communities in soil on very broad geographic scales?

The first results obtained in this programme have demonstrated:

- a non-stochastic distribution of bacterial diversity which is spatially structured in biogeographical patterns on a regional scale (Dequiedt et al., 2009),

- a taxa-area relationship for soil bacterial communities,

- a positive correlation between bacterial diversification and landscape diversity and fragmentation,

- a greater influence of local environmental local parameters (pedoclimatic and land use) as opposed to global parameters (climate and geomorphology) on bacterial community density and diversity,

- the strongly deleterious effects that specific land use (especially agriculture) can have on indigenous bacterial communities. 
RMQS : " Réseau de Mesure de la Qualité des Sols »= « French Soil Quality Monitoring Network » managed by unit INFOSOL, (INRA Orléans), soil systematic sampling grid: 16 $\mathrm{km} \times 16 \mathrm{~km}$ square, covering all the French territory $\Rightarrow 2,200$ soils

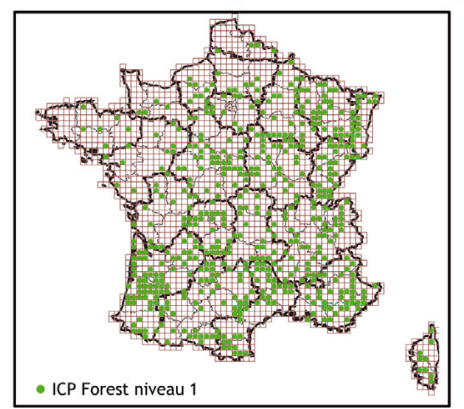

- measure of physico-chemical soil characteristics : texture, $\mathrm{pH}$, Corg tot, Norg, $\mathrm{Ca}, \mathrm{Na}, \mathrm{Mg}, \mathrm{ETM}, \ldots$ - land-cover and landscape description, GPS of soils...

\section{ECOMIC-RMQS project}

Characterization of indigeneous microbial communities (density and diversity)

Coordinated by the "Microbiology of the Soil and Environment Centre" (INRA Dijon, France)

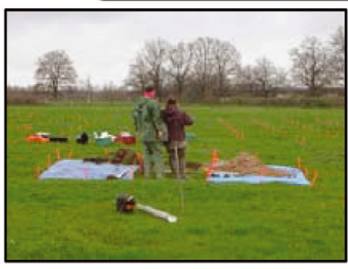

Field sampling
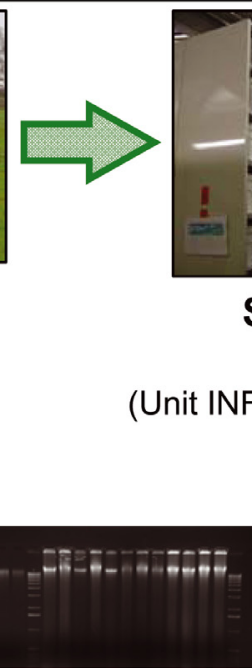

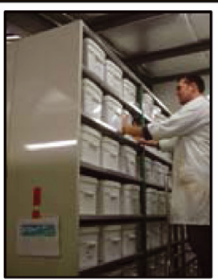

Soil Conservatory Infosol

\section{Infosol}
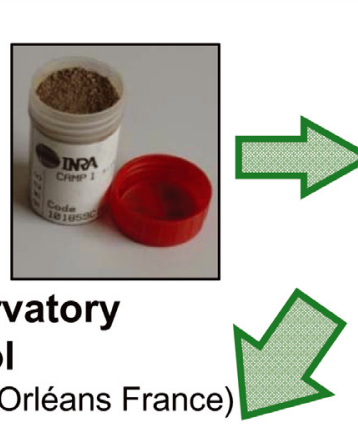

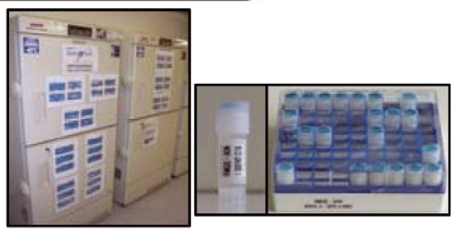

\section{Plateform GenoSol (INRA Dijon)}

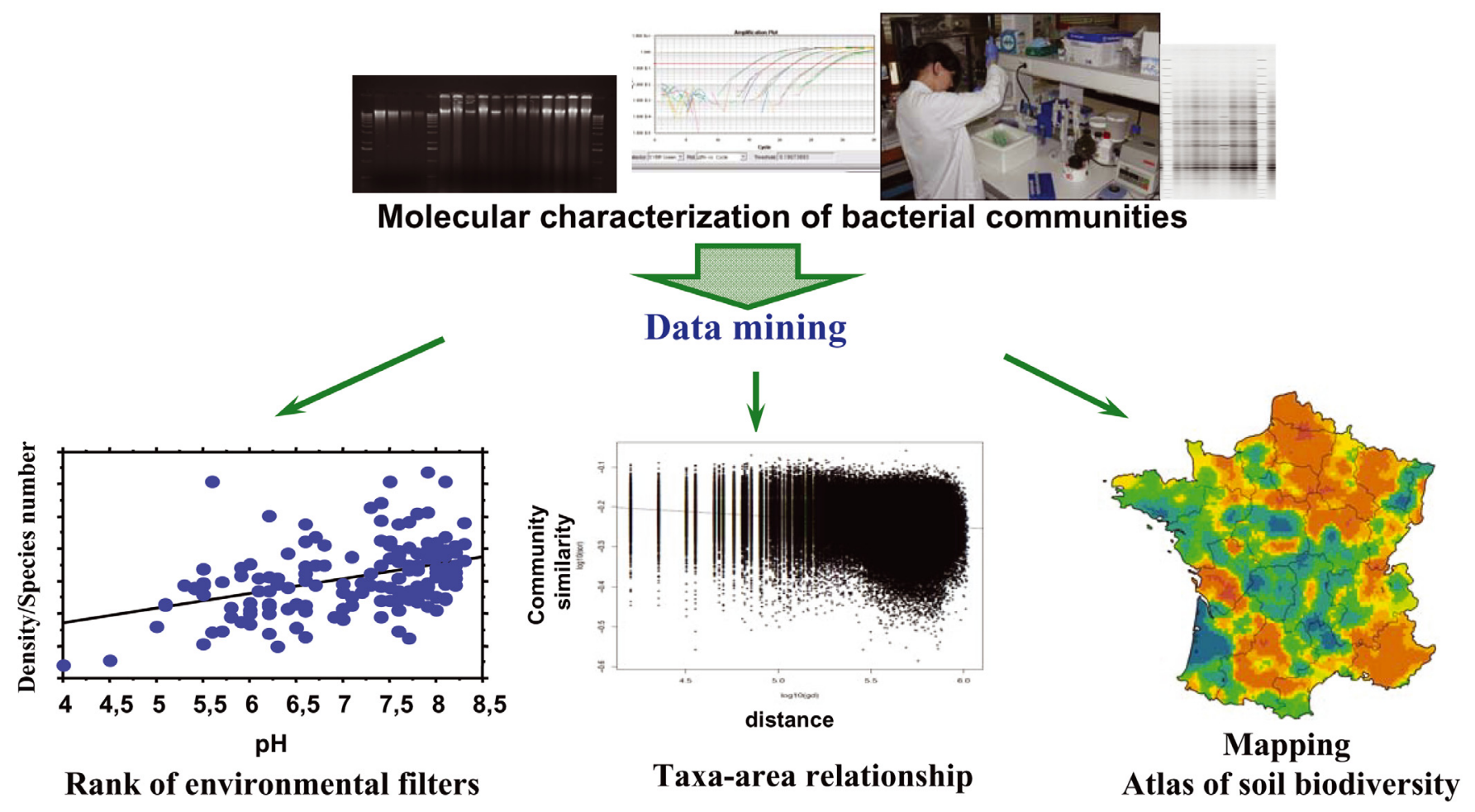

Figure 1. Schematic description of strategy and outputs of the ECOMIC-RMQS project. 


\subsection{Need for technical and logistic supports}

One of the main prerequisites of a project such as ECOMIC-RMQS, which is aimed to assess microbial diversity on a wide scale, is the development of suitable logistics for storing and managing very large numbers of biological samples and associated data. In addition, the soil samples need to be characterised under medium-throughput conditions with high levels of reproducibility and quality of the applied procedures. The GenoSol Platform, which was set up to store and manage soil samples as well as to ensure molecular characterisation of the microbial communities, meets these requirements (Ranjard et al., 2009). Thus, two complementary structures described as Soil Biological Resource Centres have been developed in France: the INFOSOL Conservatory and GenoSol Platform.

The INFOSOL unit in Orléans (France) houses the soil conservatory. This soil library has been designed for the management, storage, preparation and dissemination of soil samples from the RMQS programme in the long term. Thousands of large samples (5 to $10 \mathrm{~kg}$ each) are stored air-dried, under controlled conditions of temperature and hygrometry. The aim is to provide (i) a memory of the state of French soil, (ii) reference samples for re-analysis after other campaigns, and (iii) a soil bank for research development.

The GenoSol Platform (http://www.dijon.inra.fr/ plateforme_genosol) was created in 2008 by the "Centre de Microbiologie du Sol et de l'Environnement" (CMSE, INRA Dijon, Burgundy, France). The aim is to provide an appropriate logistic structure for the acquisition, storage and characterisation of soil genetic resources obtained by extensive sampling (several hundred to several thousand soils), on very large space and/or time scales (national soil survey, long-term experimental sites), and to make these resources readily available to the scientific community and to policy-makers. The ultimate goal is to produce a reliable reference system based on molecular characterisation (taxonomic and functional features) of soil microbial communities, that facilitates the scientific interpretation of sample analyses on large scales of time and space sampling. Another aim of the platform is the long-term storage of a library of soil genetic resources (soil DNA) to be made available to national and international scientific communities (Ranjard et al., 2009). In summary, the GenoSol Platform can be considered as a logistic and technical tool and therefore as a strategic partner for research units who wish to benefit from large-scale soil sampling without needing to develop cumbersome or circumstantial methodologies or organisations.

In the context of the ECOMIC-RMQS project, the GenoSol Platform has:

- built up and maintains a national soil DNA library which is to be made available to the scientific community as a whole in order to assess microbial diversity in the future with more powerful tools and/or other molecular analysis,

- developed in collaboration with the INFOSOL conservatory a database of the genetic structure and taxonomic diversity of microbial communities in French soils, so that an Atlas of Soil Biodiversity can be compiled on a national scale,

- established a reference frame for interpreting these analyses by (i) treating the determinants of variability of the microbial communities in soils on a hierarchical basis, and (ii) quantifying the impact of human activities on these communities.

\section{CONCLUSION}

Various lines in the studies of microbial biogeography currently available could be further developed:

- the scale of investigation could be increased by considering a whole territory or continent to permit better comparison of the different pedoclimatic regions,

- widescale soil sampling could be conducted in the long term to evaluate the influence of land use management and global changes on the evolution of soil biodiversity,

- the characterisation of soil microbial diversity could be improved by applying recent and innovative techniques such as pyrosequencing of ribosomal genes to permit exhaustive evaluation of the taxonomic diversity of indigenous communities (Christen, 2008; Roesch et al., 2007),

- soil biodiversity could be linked with soil functioning to improve management and protection of the various resources and services of soil,

- the range of variations in diversity could be described for a given pedoclimatic zone and within this zone, for a given land use. Such information could be used to interpret soil quality analyses for soil users (farmer, industrial or urban), biodiversity erosion, and to improve land use management with a view to sustainable development.

Microbial biogeography is therefore relevant at a landscape level to understanding soil biodiversity erosion brought about by natural and/or anthropogenic activities better. Even if the relationship between soil biodiversity and soil or ecosystem functions remains incomplete, such a research strategy should improve soil management in the current context of increasing ecosystem goods and services. Consequently, at the European level, a better coordination of the different national soil surveys and of the strategy employed to characterise biodiversity constitutes a challenge for the future soil protection policy in terms of sustainable development.

Acknowledgements: The ECOMIC-RMQS programme was supported by the French National Research Agency (ANR) and ADEME. Sampling was supported by a French Scientific Group of Interest on soils: the "GIS Sol", involving the French Ministry for Ecology and Sustainable Development (MEDD), the French Ministry of Agriculture (MAP), the French Institute for the Environment (IFEN), the French Environment and Energy Management Agency (ADEME), and the National Institute for Agronomic Research (INRA). We thank all the soil surveyors and technical assistants involved in sampling the sites.

\section{REFERENCES}

Amann R.I., Ludwig W., Scheider K.H. (1995) Phylogenetic identification and in situ detection of individual microbial cells without cultivation, Microbiol. Rev. 59, 143-169. 
Bass Becking L.G.M. (1934) Geobiologie of inleiding tot de milieukunde, Van Stockum \& Zoon, The Hague.

Beijerinck M.W. (1913) De infusies en de ontdekking der backterien, in: Jaarboek van de Knoniklijke Akademie van Wetenschappen, Muller, Amsterdam.

Brown J.H., Lomolino M.V. (1998) Biogeography, Sinauer, Sunderland.

Cho J.C., Tiedje J. (2000) Biogeography and degree of endemicity of Fluorescent Pseudomonas strains in soil, Appl. Environ. Microbiol. $66,5448-5456$.

Christen R. (2008) Global sequencing: a review of current molecular data and new methods available to assess microbial diversity, Microb. Environ. 23, 253-268.

Curtis T.P., Sloan W.T. (2005) Exploring microbial diversity - A vast below, Science 309, 1331-1333.

de Wit R., Bouvier T. (2006) 'Everything is everywhere, but, the environment selects'; what did Baas Becking and Beijerinck really say? Environ. Microbiol. 8, 755-758.

Dequiedt S., Thioulouse J., Jolivet C., Saby N.P.A., Lelievre M., Maron P.A., Martin M.P., Chemidlin-Prévost-Bouré N., Toutain B., Arrouays D., Lemanceau P., Ranjard L. (2009) Biogeographical patterns of soil bacterial communities, Environ. Microbiol. Report $1,251-255$.

Fenchel T. (2003) Biogeography for bacteria, Science 301, 925-926.

Fierer N., Jackson R.B. (2006) The diversity and biogeography of soil bacterial communities, Proc. Natl Acad. Sci. (USA) 103, 626-631.

Gans J., Wolinsky M., Dunbar J. (2005) Computational improvements reveal great bacterial diversity and high metal toxicity in soil, Science 309, 1387-1390.

Green J.L., Bohannan B.J.M. (2006) Spatial scaling of microbial diversity, Trends Ecol. Evol. 21, 501-507.

Green J.L., Holmes A.J., Westoby M., Oliver I., Briscoe D., Dangerfield M., Gillings M., Beatlle A.J. (2004) Spatial scaling of microbial eukaryote diversity, Nature 432, 747-750.

Horner-Devine M.C., Lage M., Hughes J.B., Bohannan B.J.M. (2004) A taxa-area relationship for bacteria, Nature 432, 750-753.

Isaksen M.F., Bak F., Jorgensen B.B. (1994) Thermophilic sulfate reducing bacteria in cold marine sediment, FEMS Microbiol. Ecol. 14, $1-8$.

Johnson M.J., Lee K.Y., Scow K.M. (2003) DNA fingerprinting reveals links among agricultural crops, soil properties, and the composition of soil microbial communities, Geoderma 114, 279-303.
Jones R.T., Robeson M.S., Lauber C.L., Hamady M., Knight R., Fierer N. (2009) A comprehensive survey of soil acidobacterial diversity using pyrosequencing and clone library analyses, ISME J. 17, 1-12.

Kibblewhite M.G., Jones R.J.A, Montanarella L., Baritz R., Huber S., Arrouays D., Micheli E., Stephens M. (2008) Environmental Assessment of Soil for Monitoring: Volume VI. Soil Monitoring System for Europe, EUR $23490 \mathrm{EN} / 6$, Office for the Official Publications of the European Communities, Luxembourg, 188 p.

Lacarce E., Le Bas C., Cousin J.-L., Pesty B., Toutain B., Houston Durrant T., Montanarella L. (2009) Data management for monitoring forest soils in Europe for the Biosoil project, Soil Use Manage. $25,57-65$.

Martiny J.B.H., Bohannan B.J.M., Brown J.H., Colwell R.K., Furhman J.A., Green J.L., Horner-devine M.C., Kane M., Krumins J.A., Kuske C.R., Morin P.J., Naeem S., Ovreas L., Reysenbach A.L., Smith V.H., Staley J.T. (2006) Microbial biogeography: putting microorganisms on the map, Nature 4, 102-112.

Morvan X.P.P., Saby N.P.A., Arrouays D., Le Bas C., Jones R.J.A., Verheijen F.G.A., Bellamy P.H., Stephens M., Kibblewhite M.G. (2008) Soil monitoring in Europe: a review of existing systems and requirements for harmonisation, Sci. Total Environ. 391, 1-12.

Papke R.T., Ward D.M. (2004) The importance of physical isolation to microbial diversification, FEMS Microbiol. Ecol. 48, 293-303.

Ranjard L., Dequiedt S., Lelievre M., Maron P.A., Mougel C., Morin F., Lemanceau P. (2009) Platform GenoSol: a new tool for conserving and exploring soil microbial diversity, Environ. Microbiol. Report $1,97-99$.

Ranjard L., Poly F., Nazaret S. (2000) Monitoring complex bacterial communities using culture-independent molecular techniques: application to soil environment, Res. Microbiol. 151, 167-177.

Ranjard L., Richaume A. (2001) Quantitative and qualitative microscale distribution of bacteria in soil, Res. Microbiol. 152, 707-716.

Roesch L., Fulthorpe R.R., Riva A., Casella G., Hadwin A., Kent A. (2007) Pyrosequencing enumerates and contrast soil biodiversity, ISME J. 1, 283-290.

Saby N., Arrouays D., Jolivet C., Boulonne L., Pochot A. (2006) Geostatistical assessment of lead in soil around Paris, France, Sci. Total Environ. 367, 212-221.

Torsvik V., Øvreås L. (2002) Microbial diversity and function in soil: from genes to ecosystems, Curr. Opin. Microbiol. 5, 240-245. 